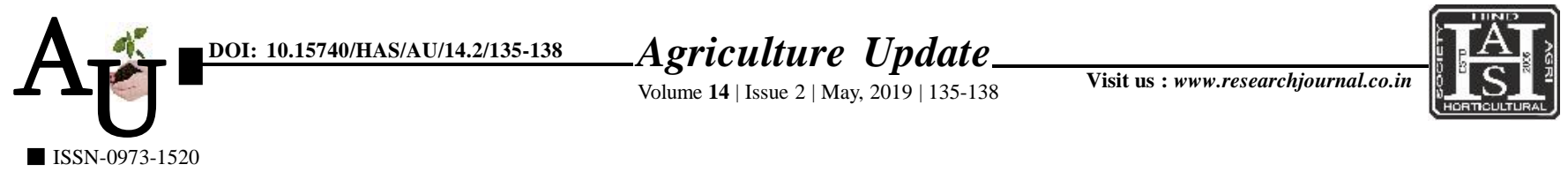

\title{
Research Article: To compare the productivity level of important crops between KCC holders and non-KCC holders
}

\author{
Amit Kumar Keshri, D.K. Bose and E.P.K. Das
}

Article Chronicle: Received :

26.11.2018;

Revised :

10.04.2019;

Accepted :

11.05.2019

KEY WoRds:

SUMMARY : The present investigation was conducted in Bikaner district of Rajasthan. Block Bikaner was selected purposively due to its maximum and $\mathrm{KCC}$ scheme was prevelant therein. 10 villages were selected purposively from the selected block as KCC scheme was operating therein. $75 \mathrm{KCC}$ holders and $75 \mathrm{KCC}$ non-holders were selected on the basis of probability proporsinate procedure. Thus, total number of respondents were 150. Most of the KCC holders (38.67\%) were under middle age group whereas 37.33 per cent KCC holders were under young age group. Most of the holders 58.67 per cent belonged to OBC caste. 45.33 per cent holders were educated from primary to middle school. Majority of KCC holder were big farmers. Annual income of 41.33 per cent KCC holders was 3-6 lakhs. There was highly significant between KCC holder and KCC Non-holders in context of their productivity of (moth, groundnut, cluster bean, wheat, mustard and gram).

How to cite this article : Keshri, Amit Kumar, Bose, D.K. and Das, E.P.K. (2019). To compare the productivity level of important crops between KCC holders and non-KCC holders. Agric. Update, 14(2): 135-138; DOI : 10.15740/HAS/AU/14.2/135-138. Copyright@ 2019: Hind Agri-Horticultural Society.

KCC, Comparison,

Productivity,

Important crop

Author for correspondence :

\section{Amit Kumar Keshri}

Department of

Agricultural Extension

and Communication,

Sam Higginbottom

University of

Agriculture, Technology

and Sciences, Allahabad

(U.P.) India

Email: amit_keshri087

@ yahoo.in

See end of the article for

authors' affiliations 